PENGARUH MODEL KOOPERATIF TIPE TEAM ASSISTED

\title{
INDIVIDUALIZATION (TAI) TERHADAP HASIL BELAJAR TEMATIK TERPADU MUATAN IPS SISWA KELAS IV SDN 101/II MUARA BUNGO
}

\author{
Yeni Anggraini ${ }^{1)}$ \\ Gingga Prananda ${ }^{2)}$ \\ Deded Pratama ${ }^{3)}$
}

Fakultas Keguruan Dan Ilmu Pendidikan Universitas Dharmas Indonesia yenia8632@gmail.com

\begin{abstract}
ABSTRAK: Hasil belajar siswa pada mata pelajaran IPS masih banyak yang belum mencapai Kriteria Ketuntasan Minimum (KKM), hal ini karena kurangnya teknik yang diterapkan untuk membantu proses pembelajaran. Penelitian ini bertujuan untuk mengetahui pengaruh penggunaan Team Assisted Individualization terhadap hasil belajar siswa pada mata pelajaran IPS materi Lingkungan Tempat Tinggalku pada siswa kelas IV SDN 101/II Muara Bungo. Jenis penelitian eksperimen ini berbentuk Quasy Experimental Design (Nonequivalent control group design). Sampeldiambil secara purposive sampling dan dibagi menjadi 2 kelompok, yaitu kelompok eksperimen dan kelompok kontrol.Instrumen penelitian yang digunakan adalah Tes Pilihan ganda. Teknik pengumpulan data yang di gunakan adalah pre-test dan post-test dengan membandingkan hasil akhir (post-test) siswa. Hasil penelitian menunjukkan bahwa ada pengaruh pada pengaruh model kooperatif tipe Team Assisted Individualization terhadap hasil belajar IPS. Hal tersebut di buktikan dari rata-rata post-test yaitu dengan pengaruh model kooperatif Team Assisted Individualizatio sebesar 76,52 sedangkan dengan metode konvensional sebesar 66,13. Hasil penelitian di kelas eksperimen dimana nilai tertinggi 95, dan di kelas kontrol nilai tertinggi nya sebesar 95. Uji hipotesis menggunakan uji t (t-test) dari hasil perhitungan yang diperoleh sig $<(0,000<0,05)$ dan $(0,40<0,05)$ yang berarti uji t tidak berada pada daerah penerimaan $\mathrm{H} 0$ sehingga dapat disimpulkan bahwa H0 ditolak dan Ha diterima pada taraf nyata 0,05.Maka dapat disimpulkan bahwa penerapan Team Assisted Individualization memberikan pengaruh yang signifikan terhadap peningkatan hasil belajar siswa kelas IVA SDN 101/II Muara Bungo.
\end{abstract}

Kata Kunci :Model Pembelajaran Team Assisted Individualization

ABSTRACT:Many students' learning outcomes in social studies subjects have not reached the Minimum Completeness Criteria (KKM), this is due to the lack of techniques applied to assist the learning process. This study aims to determine the effect of the use of Team Assisted

91 | Jurnal CONSILIUM (Education and Counseling Journal) 
Individualization on student learning outcomes in the Social Sciences subject for the environment where I live in fourth grade students of SDN 101/II Muara Bungo. This type of experimental research is in the form of Quasy Experimental Design (Nonequivalent control group design). Samples were taken by purposive sampling and divided into 2 groups, namely the experimental group and the control group. The research instrument used is a multiple choice test. Data collection techniques used are pre-test and post-test by comparing the final results (post-test) of students. The results showed that there was an influence on the effect of the Team Assisted Individualization type cooperative model on social studies learning outcomes. This is proven from the post-test average, namely the influence of the Team Assisted Individualizatio cooperative model of 76.52 while the conventional method is 66.13 . The results of the study in the experimental class where the highest score was 95, and in the control class the highest score was 90. Hypothesis testing using the t-test (t-test) from the calculation results obtained sig $<(0.000<0.05)$ and $(0.40<0,05)$ which means that the $t$ test is not in the area of acceptance of H0 so it can be concluded that $\mathrm{HO}$ is rejected and $\mathrm{Ha}$ is accepted at a significance level of 0.05 . So it can be concluded that the implementation of Team Assisted Individualization has a significant effect on improving student learning outcomes for class IVA SDN 101/II Muara Bungo.

Keywords :Team Assisted Individualization Learning Model

\section{PENDAHULUAN}

Pendidikan adalah pengaruh lingkungan atas individu untuk menghasilkan perubahan-perubahan yang tetap didalam kebiasaan-kebiasaan, pemikiran, sikap-sikap, dan tingkah laku. Sejalan dengan padangan harus diyakini bahwa fungsi utama pendidikan adalah bimbingan terhadap individu dalam upaya memenuhi kebutuhan dan keinginan yang sesuai dengan potensi yang dimilikinya sehinggan memperoleh kepuasan dalam seluruh aspek kehidupan pribadi dan kehidupan sosialnya (Mikarsa,dkk : 2007).

Belajar merupakan proses yang berhubungan antara guru dan siswa. Peristiwa pembelajaran terjadi apabila siswa secara aktif berinteraksi dengan lingkungan belajar yang diatur guru.Proses perubahan di dalam keperibadian manusia dan perubahan tersebut ditampakkan dalam bentuk peningkatan kualitas dan kuantitas tingkah laku seperti peningkatan kecakapan, pengetahuan, sikap, kebiasaan, pemahaman, keterampilan, daya pikir dan kemampuan- kemampuan yang lain (Prananda, 2019).

Pendidikan menurut Undang-Undang Republik Indonesia Nomor 2 Tahun 1989 tentang Sistem Pendidikan Nasional atau yang lebih dikenal dengan sebutan UndangUndang Sistem Pendidikan Nasional (UUSPN) pasal 1 ayat 1 pendidikan adalah usaha 
sadar untuk menyipakan peserta didik melalui kegiatan bimbingan, pengajaran dan latihan bgi peranan di masa depan yang akan datang.

Pendidikan merupakan upaya nyata yang dilakukan dengan penuh kesadaran, teratur, terarah, dan berencana atau bertahap dalam mengembangkan kemampuan dan kepribadian manusia agar dapat berkompetisi dalam lingkup kehidupan yang berlangsung di rumah, di sekolah, dan di masyarakat.Pendidikan juga merupakan suatu kebutuhan bagi manusia, baik sebagai makhluk sosial maupun individu. Pendidikan adalah usaha pendidik untuk memimpin anak didik secara umum guna mencapai perkembangannya menuju kedewasaan jasmani maupun rohani. Peningkatan kualitas pendidikan di sekolah dapat ditempuh melalui berbagai cara salah satunya dengan meningkatkan kualitas pembelajaran Guru harus dapat memahami cara siswa belajar agar dapat menentukan model pembelajaran yang tepat sehingga tujuan pembelajaran tercapai dengan baik sesuai dengan kurikulum 2013. Sedangkan yang digunakan, kurikulum 2013 siswa dituntut melalui beberapa proses secara aktif mencari,mengolah, mengkonstruksi dan menerapkan pengetahuan maka sangat diperlukan upaya inovasi guru dalam mendalami pembelajaran di kelas. Pembelajaran disajikan menggunakan pendekatan tematik semua mata pelajaran disajikan dalam bentuk tema, sehingga yang ada bukan buku permata pelajaran, tetapi buku per tema. Pembelajran tematik di sekolah dasar atau SD merupakan bentuk pelajaran yang memadukan beberapa mata pelajaran yakni: Basaha Indonesia, IPA, IPS, PPKn, SBdP yang dilaksanakan secara terpadu dari semua muatan mata pelajaran dalam satu kali pembelajaran dengan maksud untuk memberikan secara langsung pengalaman dan pengetahuan bagi siswa. Dalam proses pembelajaran siswa dibekali dalam berbagai mata pelajaran salah satunya adalah pembelajaran tematik terpadu muatan IPS(Wulandari\& Sujana, 2014).

Ilmu pengetahuan sosial (IPS) merupakan integrasi dari berbagi cabang ilmu-ilmu sosial dan humaniora, yaitu sosiaologi, sejarah, geografi, ekonomi, politik, hukum, dan budaya. Ilmu pengetahuan sosial dirumuskan atas dasar realitas dan fenomena sosial yang mewujudkan satu pendekatan interdisipliner dari aspek dan cabang-cabang ilmu sosial. Pelajran IPS di SD mengajarkan konsep-konsep esensi ilmu sosial untuk membentuk subjek didik menjadi warga Negara yang baik. Istilah IPS mulai digunakan 
secara resmi di Indonesia sejak tahun 1975 adalah istilah indonesia untuk Social Studies di amerika (Susanto, 2014).

IPS adalah mata pelajaran yang mempelajari kehidupan sosial yang didasarkan pada kajian geografi, ekonomi, sosiologi, antropologi, tata negara dan sejarah, dalam ilmu pengetahuan sosial atau yang disingkat menjadi IPS merupakan salah satu mata pelajaran yang terdapat dalam kurikulum pendidikan di Indonesia, termasuk pada jenjang sekolah dasar (Wulandari\& Sujana, 2014).

Berdasarkan hasil obsevasi yang ditemukan beberapa permasalahan pada hari senin 08 Maret 2021 saat penulis masuk ke kelas IV melakukan observasi bersama guru kelas ketika melaksanakan proses belajar mengajar, penulis melihat permasalahannya yang ada dalam kelas IV salah satunya pada pembelajaran Tematik Terpadu muatan IPS pada Tema 8 Subtema 1 "Tentang Daerah Tempat Tinggalku", di sekolah dasar terlihat siswa kurang bersemangat dengan pembelajaran Tematik Terpadu muatan IPS sehingga menimbulkan tidak adanya timbal balik antara guru dan siswa. Ketika proses pembelajaran berlangsung guru yang lebih banyak berperan aktif dari pada siswa, terlihat juga suasana kelas tidak terkondisikan, pembelajaran Tematik Terpadu muatan IPS juga kurang menarik perhatian siswa. Karena menggunakan metode ceramah dan Tanya jawab. Lebih banyak diam dan tidak memperhatikan guru saat pembelajaran dilaksanakan dikarenakan tidak memahami materi yang dijelaskan sehingga kurang dimengerti oleh siswa, siswa juga tidak aktif ketika proses pembelajaran berlangsung dan mengakibatkan hasil belajar siswa rendah. Hasil belajar siswa dapat dilihat dari nilai ulangan harian semester ganjil kelas IV SD Kabupaten Muara Bungo dapat dilihat dari tabel 1.1:

Table 1. 1 Nilai UH semester ganjil kelas IVA SDN 101/ II Muara Bungo

\begin{tabular}{|c|l|c|c|c|c|}
\hline \multirow{2}{*}{ No Kelas } & \multicolumn{2}{|c|}{ Tuntas } & \multicolumn{2}{c|}{ Tidak Tuntas } \\
\cline { 3 - 6 } & & 7 & 35 & 16 & 66 \\
\hline $\mathbf{l}$ & IV A & 6 & 25 & 16 & 75 \\
\hline $\mathbf{2}$ & IV B & \multicolumn{2}{|c|}{13} & \multicolumn{2}{|c|}{32} \\
\hline \multicolumn{2}{|c|}{ Jumlah siswa } & & \multicolumn{3}{|c|}{} \\
\hline
\end{tabular}

Berdasarkan tabel di atas menunjukkan bahwa ulangan harian Semester Ganjil Kelas IV SD Negeri 101/II Muara Bungo sebagian besar belum tercapai kriteria 
ketuntasan minimum (KKM) yang telah ditetapkan sekolah yaitu 70. Hal ini dapat dilihat dari 45 siswa hanya beberapa siswa yang mencapai KKM.

Berdasarkan masalah diatas solusi yang digunakan penulis dalam mengatasi permasalahan yang ada pada pembelajaran tematik terpadu muatan IPS yang sangat berkaitan dengan pemahaman siswa dan lingkungan sekitar siswa. Pembelajaran tematik terpadu muatan IPS sebenarnya pembelajaran yang menyenangkan dan berkaitan dengan lingkungan sosial yang ada di masyarakat. Untuk meningkatkan hasil belajar dengan penggunaan model koopeatif tipe Team Assisted Individualization (TAI) yang sangat menekankan pada perkembangan kemampuan anak yang akan memberi keaktifan pada anak dalam belajar bersama dengan kelompok-kelompok yang bertanggung jawab dan para siswa dapat termotivasi dalam belajar bersama tersebut. Sehingga pembelajaran melalui model Team Assisted Individualization (TAI) ini dianggap sangat bermakna memberikan kesempatan pada siswa untuk belajar sesuai dengan perkembangan dan perubahan tingkah laku siswa melalui pengalaman yang dimilikinya. Serta dapat mempengaruhi hasil belajar siswa dikelas agar menjadi lebih baik dan mengurangi tingkat kebosanan siswa pada pembelajaran Tematik Terpadu muatan IPS. Dalam menjadikan suasana belajar yang menarik dan afektif, dengan adanya kelompok kecil yang mempengaruhi hasil belajar Tematik Terpadu Muatan IPS, sehingga akan tercapai tujuan pembelajaran siswa dengan baik dan memuaskan. Siswa dapat berperan aktif dan ikut berpartisipasi dalam mendiskusikan masalah yang ada dalam kelompok yang diajukan oleh guru. Sehingga terjadilah timbal balik antara siswa dan guru ketika proses pembelajaran berlangsung.

Berdasarkan latar belakang di atas penulis memfokuskan penelitian dengan judul "Pengaruh Model Kooperatif Tipe Team Assisted Individualization (TAI) Terhadap Hasil Belajar Tematik Terpadu Muatan IPS”

\section{METODE PENELITIAN}

Jenis penelitian yang digunakan dalam penelitian ini adalah eksperimen semu (Quasy Experimental Design). Menurut Sugiyono (2016)Quasy Exkperimental Design merupakan pengembangan dari true experimental design,yang sulit dilaksanakan desain 
ini mempunyai kelompok control, tetapi tidak berfungsi sepenuhnya untuk mengontrol variabel-variabel luar yang mempengaruhi pelaksaan eksperimen.

Desain penelitian dalam penelitian ini menggunakan nonequivalent control group desain. Nonequivalent control group desain hampir sama dengan pre-test dan pos-stest, hanya pada desain ini kelompok eksperimen maupun kelompok control tidak dipilih secara random. Dari kedua kelompok tersebut yang satu di jadikan kelas eksperimen (diberi perlakuan) dan yang satu dijadikan kelompok kontrol (tidak di beri perlakuan). Sebelum dilakukan perlakuan, terhadap kedua kelompok tersebut dilakukan pre-test, selanjutnya kelompok eksperimen di beri perlakuan sedangkan kelompok kontrol tidak diberi perlakuan dan selanjurnya dilakukan post-test sesudah deberikan perlakuan.

Adapun gambaran desain penelitian menurut Sugiyono (2016) sebagai berikut :

I

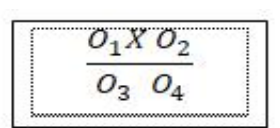

Gambar 3. 1 Nonequivalent control group design.

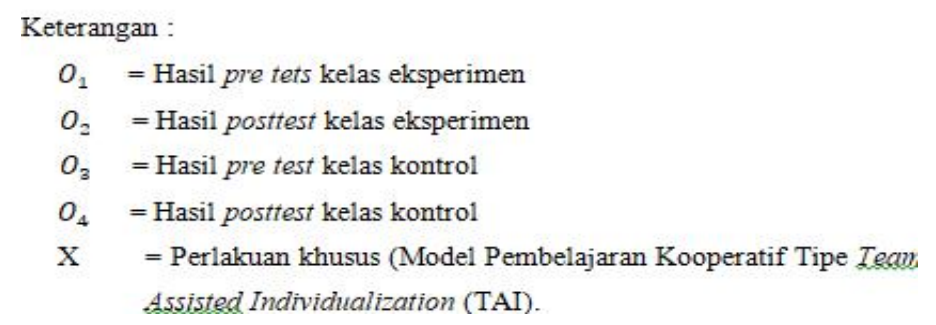

\section{HASIL DAN PEMBAHASAN}

Pada bagian ini akan diuraikan hasil yang ditemukan dalam penelitian yang dilaksanakan pada 9 juni 2021 sampai 15 juni 2021. Hasil yang dimaksudkan yaitu kesimpulan yang diambil berdssasarkan data yang terkumpul dan analisis data yang telah dilakukan.

Hasil analisis data tes akhir belajar didapatkan nilai rata-rata belajar siswa menunjukkan bahwa penggunaan Pengaruh Model Kooperatif Tipe Team Assisste Individualization pada mata pelajaran IPS. Hasil ini terlihat dari tingginya rata-rata hasil belajar siswa yang belajar dengan menggunakan Pengaruh Model Kooperatif Tipe Team Assisted Individualization di bandingkan dengan nilai siswa yang tidak menggunakan 
Pengaruh Model Kooperatif Tipe Team Assisted Individualization dalam proses pembelajaran.

Hasil belajar siswa diperolah nilai rata-rata kelas eksperimen sebesar 76,5, sedangkan nilai rata-rata kelas kontrol 66,13, nilai ini menunjukkan hasil belajar IPS pada ranah kognitif rata-rata nilai kelas eksperimen lebih tinggi dari pada kelas kontrol. Sebagaimana yang diunggkapkan (Susanto, 2014) hasil belajar yaitu sebagai tingkat keberhasilan siswa dalam mempelajari materi pelajaran di sekolah yang dinyatakan dalam skor yang diperoleh dari hasil tes mengenai sejumlah materi pelajaran tertentu. Hasil perhitungan menunjukkan ketuntasan belajar siswa secara individu kelas eksperimen diatas kriteria ketuntasan minimum (KKM) mata pelajaran IPS yang ditetapkan oleh sekolah bersangkutan yaitu 75. Perolehan nilainya dapat dirinci sebagai dengan jumlah 45 orang siswa dari 23 orang siswa dikelas eksperimen sedangkan 22 orang siswa di kelas kontrol, terlihat bahwa pada kelas eksperimen siswa memperoleh nilai di atas KKM lebih banyak dari pada di kelas kontrol.

Hasil uji normalitas dan homogenitas yang dilakukan pada ranah kognitif, di dapatkan kedua kelas sampel normal dan mempunyai variasi yang homogeny, sehingga untuk statitistic digunakan uji t. Hasi uji t menggunakan signifikan dan taraf nyata 0,05 yang di dapatkan sig $>\alpha$. Hal ini berarti H0 di tolak dan Ha diterima yang berbunyi “Terdapat pengaruh yang signifikan pada pembelajaran yang menggunakan Pengaruh Model Kooperatif Tipe Team Assisted Individualization.

Pencapaian kompetensi belajar akan lebih optimal apabila guru sebelum merancang program dan kegiatan pembelajaran harus lebih dahulu membangkitkan motivasi belajar siswa. Upaya menumbuhkan motivasi dan minat belajar siswa dapat dilakukan melalui penerapan strategi yang efektif dalam proses pembelajaran. Penggunaan Pengaruh Model Kooperatif Tipe Team Assisted Individualization dapat memotivasi dan menarik minat siswa untuk mengikuti pembelajaran.

Penelitian yang telah dilaksanakan mendapatkan hasil, bahwa pengaruh model kooperatif tipe team assisted individualization memiliki pengaruh yang cukup signifikan terhadap hasil belajar siswa kelas IV. Perhitungan pengujian hipotesis yang menyatakan bahwa diterima yang berarti pengaruh model kooperatif tipe team assisted individualization memiliki pengaruh terhadap hasil belajar IPS siswa kelas IV. Hal ini 
dipertegas dengan hasil perhitungan pada uji-t dengan menggunakan t,tes yang diperoleh sebesar dengan demikian Pengaruh Model Kooperatif Tipe Team Assisted Individualization memberikan pengaruh yang cukup baik terhadap hasil belajar siswa. Selain itu, dalam pembelajaran menggunakan Pengaruh Model Kooperatif Tipe Team Assisted Individualization ini, memberikan motivasi tersendiri dalam kegiatan pembelajaran. Hal ini terlihat jelas melalui respon yang dapat melalui pembelajaran dengan pengaruh ini. Siswa lebih antusias dalam mengikuti pelajaran dengan melakukan beberapa percobaan-percobaan ilmiah. Siswa sangat berminat untuk melakukan percobaan-percobaan yang dilakukan secara berkelompok, selain itu siswa juga sangat memperhatikan pengarahan yang diberikan oleh guru. Kerjasama dan partisipasi antar siswa lain dapat terlihat dengan jelas melalui percobaan-percobaan yang di lakukan sehingga mereka dapat bertukar pikiran dengan baik antar sesame siswa lain.

Pembelajaran yang diterima kelas kontrol merupakan pembelajaran yang bisa dilakukan guru yaitu dengan konvesional. Hasil pengamatan pada siswa kelas kontrol menunjukkan bahwa siswa kurang antusias dalam mengikuti proses pembelajaran.

Sedangkan pembelajaran pada kelas eksperimen menggunakan Pengaruh Model Kooperatif Tipe Team Assisted Individualization,Pengaruh Model Kooperatif Tipe Team Assisted Individualizationdalam pembelajarannya dilakukan dengan kehidupan nyata siswa sebagaimana yang disampaikan dalam buku (Trianto) menyatakan bahwa Team Assisted Individualizationmerupakan konsep belajar yang membantu guru mengaitkan antara materi yang di ajarkan dengan situasi dunia nyata siswa dan mendorong siswa membuat hubungan antara pengetahuan yang dimilikinya dengan penerapan dalam kehidupan sehari hari mereka sebagai anggota keluarga dan masyarakat. Dengan kensep itu, hasil pembelajaran yang diharapkan lebih bermakna bagi siswa Pengaruh Model Kooperatif Tipe Team Assisted Individualizationdapat menjadikan siswa lebih memahami makna di dalam pelajaran dengan menghubungkan dengan kehidupan mereka sehari-hari, yaitu dengan lingkungan pribadi. Dalam penelitian ini yang diajarkan lingkungan tempat tinggalku.

Siswa kelas eksperimen lebih memahami isi dari bahan yang diajarkan karena siswa belajar dengan lingkungan disekitarnya. Sehingga hasil belajar IPS siswa kelas 
eksperimen menjadi lebih baik, menjadikan siswa lebih aktif dan memberikan pengalaman yang berkesan bagi siswa. Hal ini menunjukkan bawah Pengaruh Model Kooperatif Tipe Team Assisted Individualization berpengaruh terhadap hasil belajar siswa kelas IV SD Negeri 101/II Muara Bungo.

\section{KESIMPULAN}

Berdasarkan hasil dan pembahasan penelitian dapat disimpulkan bahwa pembelajaran yang menggunakan Pengaruh Model Kooperatif Tipe Team Assisted Individualization dapat mempengaruhi hasil belajar siswa pada pembelajaran IPS dikelas IV SDN 101/II Muara Bungo. Hal ini ditunjukkan dengan hasil uji-tindependent Sampel Test perhitungan diperoleh $\operatorname{sig}<\alpha(0,000<0,05)$ dan $(0,234<0,05)$ yang berarti uji t tidak berada pada daerah penerimaan H0 sehingga dapat disimpulkan bahwa H0 ditolak dan Ha diterima pada taraf nyata 0,05 .

Bukti ini juga diperkuat dengan adanya peningkatan jumlah siswa yang memperoleh nilai KKM setelah penerapan Team Assisted Individualizationpada kelas eksperimen, dimana sebelum penerapan Team Assisted Individualization, jumlah siswa yang tidak mencapai KKM sebesar 78\%. Sedangkan setelah menggunakan penerapan Team Assisted Individualization, siswa yang tidak mencapai KKM hanya 17\%. Maka dapat disimpulkan bahwa Pengaruh Model Kooperatif Tipe Team Assisted Individualization memberikan pengaruh yang signifikan terhadap peningkatan hasil belajar siswa kelas IVA SDN 101/II Muara Bungo.

99 | Jurnal CONSILIUM (Education and Counseling Journal) 


\section{SARAN}

Berdasarkan kesimpulan yang telah dikemukakan di atas, maka penulis dapat memberikan saran sebagai berikut.

1. Hasil penelitian membuktikan ternyata, pembelajaran dengan menggunakan Model Team Assisted Individualization berpengaruh positif terhadap hasil belajar siswa, maka disarankan penggunaannya lebih ditingkatkan lagi, sehingga hasil belajar siswa bisa lebih meningkat.

2. Bagi siswa sendiri, diperlukan tuangan ide dari murid-murid untuk lebih mengembangkan atau menciptakan Model Team Assisted Individualization dalam pembelajaran, baik pembelajaran intern maupun ekstern.

3. Bagi peneliti, selesainya penelitian bukan berarti selesainya kreativitas peneliti, anggaplah penelitian dan hasil penelitian yang di dapat merupakan awal mula seorang guru memulai kreativitasnya.

Bagi peneliti lain, penelitian yang peneliti lakukan masih kurang sempurna, bagi peneliti lain alangkah baiknya mengembangkan kreatifitasnya tiada henti dan menarik untuk di teliti. 


\section{DAFTAR RUJUKAN}

Mikarsa Hera Lestari, Agus Taufik, P. L. P. (2007). Pendidikan Anak DI SD. Universitas Terbuka.

Wulandari Putu Wulandari,Sujana I Wayan, N. N. G. (2014). Pengaruh Penerapan Model Pembelajaran Kooperatif Tipe Team Accelerated Instruction ( Tai ) Terhadap Hasil Belajar Ips Siswa Kelas V Sd Gugus Viii Kedewatan Kecamatan Ubud Gianyar Jurusan Pendidikan Guru Sekolah Dasar , Fip Universitas Pendidikan Ganesha N. Mimbar Pgsd Universitas Pendidikan Ganesha, 2(1)

SusantoAhmad. (2014). Pengembangan Pembelajaran Ips Disekolah Dasar. Prenada Media Group.

Sugiyono. (2016). Metode Penelitian kuantitatif,kualitatif dan $R \& D$. alfabeta cv.

ShoiminAris. (2014). 68 Model Pembelajaran Inovatif dalam Kurikulum 2013. Ar-Ruzz Media.

Dimyati \& Mudjiono. (2009). Belajar \& Pembelajaran. PT.RINEKA CIPTA

Sari Dyah Ika Puspita. (2010). Penerapan Pembelajaran Kooperatif Tipe Team Assisted Individualization (Tai) Untuk Meningkatkan Aktivitas Dan Hasil Belajar Siswa Dalam Pembelajaran Pkn Di Smp N 2 Tempel.

Kristin, F. (2016). Jurnal Pendidikan Dasar PerKhasa Volume 2, Nomor 1, April 2016 ANALISIS MODEL PEMBELAJARAN. 2(April).

Adnyani Ni Wayan Nopi, I. K. G. \& I. M. C. W. (2015). Pengaruh Model Pembelajaran Kooperatif Tipe TAI Dan Motivasi Berprestasi Terhadap Hasil Belajar IPS Siswa. E-Journal PGSD Universitas Pendidikan Ganesha, Vol: 3 No:(1)

Ahmad Susanto. (2014). Pengembangan Pembelajaran IPS disekolah dasar. Prenada Media Group.

Hera Lestari Mikarsa, Agus Taufik, P. L. P. (2007). Pendidikan Anak DI SD. Universitas Terbuka. 
Prananda, G. (2019). Pengaruh Model Pembelajaran Kooperatif Tipe STAD Dalam Pembelajaran IPA Siswa Kelas V SD. Jurnal Pedagogik, 6(1), 122-130.

Putu Yuny Wulandari, I Wayan Sujana, N. N. G. (2014).Pengaruh Penerapan Model Pembelajaran Kooperatif Tipe Team Accelerated Instruction ( Tai ) Terhadap Hasil Belajar Ips Siswa Kelas V Sd Gugus Viii Kedewatan Kecamatan Ubud Gianyar Jurusan Pendidikan Guru Sekolah Dasar , Fip Universitas Pendidikan Ganesha N. Mimbar Pgsd Universitas Pendidikan Ganesha, 2(1). 